Kong. Res. J. 1(2): 126-130, 2014

Kongunadu Arts and Science College, Coimbatore

\title{
ANTI-HYPER LIPIDEMIC ACTIVITY OF METHANOLIC EXTRACT OF SMILAX WIGHTII A.DC. IN STREPTOZOTOCIN INDUCED MALE WISTAR ALBINO RATS
}

\author{
Uma Maheswari, $P^{*}$., K. Arumugasamy, A. Shalimol, V. Asha devi and R. Nantha kumar \\ Department of Botany, Kongunadu Arts and Science College, Coimbatore. \\ *E-mail: umascience@gmail.com
}

\begin{abstract}
Smilax wightii, an endemic medicinal plant is found in the shola forests at high altitudes in Nilgiri Biosphere Reserve, the Western Ghats, Southern India . The present study, was undertaken to find out the effect of methanolic extract of this plant on the body weight, fasting blood glucose levels and lipid profiles in all the streptozotocin (STZ) induced rats. The extract exerted a significant $(\mathrm{P}<0.05)$ effect in the body weight of the experimental animals when compared to the control group. Treatment with the extract and glibenclamide resulted in a significant $(\mathrm{P}<0.01)$ reduction in the fasting blood glucose levels in diabetic rats when compared to the normal. The lipid profile such as TC, TG, LDL, and VLDL contents in the serum registered a significant $(\mathrm{P}<0.01)$ hike and a decline in the HDL contents in diabetic control group, which were retrieved to near normalcy in the plant extract treated groups. The effect produced by this plant extract was comparable with that of glibenclamide. The decreased fasting blood glucose levels and lipid lowering properties clearly showed the anti-hyperlipidemic effect of S.wightii.
\end{abstract}

Key words: Smilax wightii, anti-hyperlipidemic, streptozotocin, glibenclamide

\section{INTRODUCTION}

Traditional medicinal herbs have served as a potential alternative source of medicine and different healthcare systems (Kamboj, 2000). Diabetes mellitus is a metabolic disorder, characterized by hyperglycemia together with impaired metabolism of glucose and other energyyielding fuels such as lipids and proteins (Scheen, 1997). In modern medicine, no satisfactory effective therapy is still available to cure the diabetes mellitus (Piedrola et al., 2001). Herbal treatments are becoming popular as the herbal preparations have no or least side effects and also they are of relatively low cost (Rajasekaran et al., 2001).

The genus Smilax has more than 300 species, found on temperature zones, tropic and subtropics worldwide and belongs to Smilacaceae (Fnaec, 2000). The roots of Smilax wightii have been reported to cure dysentery, amoebiasis, veneral diseases, urinary complaints, fever, spermatorrhoea, antifertility, anaemia, rheumatic-arthritis, veterinary amoebiasis and gastric complaints (Adhikari et al., 2010). The species of Smilax have been reported to contain several phytoconstituents such as dioscin, steroids smilagenin and sarsapogenin (Coimbatore BSI, 1989). Several species of Smilax are used in Chinese traditional system of medicines as anticancer, anti-inflammatory and analgesic agents (Ozoy et al., 2008). Therefore, the present study was aimed to assess the anti-hyperlipidemic effects of methanolic extract of Smilax wightii in animal models.

\section{MATERIALS AND METHODS}

\subsection{Plant material}

The plant materials were collected from Kodanadu, the Nilgiri Hills, Western Ghats, Southern India, Tamil Nadu. The plant was identified and authenticated by a plant taxonomist.

\subsection{Preperation of extract}

The whole plant materials were dried in shade after washing with cold water and then powdered using pulveriser and passed through sieve. About $100 \mathrm{~g}$ of dried plant powder was extracted with petroleum ether using soxhlet apparatus for 18 hours. The petroleum ether was evaporated from the extract and then the residue was re-extracted with methanol. This extract after evaporation of methanol, the filtered residue was stored at $4^{\circ} \mathrm{C}$ in refrigerator for further use.

\subsection{Experimental animals}

Male Wistar Albino rats weighing180-250 g were obtained from Agricultural University, Animal house lab, Trissur, Kerala. The animals were fed on a standard pellet diet (Hindustan Lever, Kolkata, India) and water ad libitum. They were maintained in a controlled environment ( $12 \mathrm{~h} / 12 \mathrm{~h}$ light/dark) and temperature $\left(25 \pm 2^{\circ} \mathrm{C}\right)$. The animals were acclimatized to the laboratory conditions for one week before starting the experiment. All the 
procedures performed on animals were approved and conducted in accordance with the Institution of Animal Ethics committee and by the Regulatory body of the government (659/02/a/CPCSEA).

\subsection{Toxicity studies}

The acute toxicity studies were performed in adult male albino rats weighing180-250g. The animals were fasted overnight and $100-1000 \mathrm{mg} / \mathrm{kg}$ of the test extract was provided to various groups containing six animals in each group. The treated animals were monitored for 14 days, for behaviour, general health and mortality.

\subsection{Induction of diabetes}

Diabetes was induced in overnight fasted Wistar albino rats by intraperitoneal (i.p injection of streptozotocin at a dose of $55 \mathrm{mg} / \mathrm{kg}$ b.wt. Forty eight hours after streptozotocin administration, blood samples were drawn from tail and glucose levels were determined to confirm diabetes. The rats with blood glucose level above $200 \mathrm{mg} / \mathrm{kg}$ were considered diabetic and used for the study.

\subsection{Experimental design}

The rats were divided into six groups comprising of six animals in each group as follows:

Group I. : - Rats given normal saline daily for 14 days, orally (by using an intragastric catheter tube (IGC). ( Normal control)

Group II:- Diabetic rats given normal saline daily for 14 days , orally by using IGC. (Diabetic control)

Group III: - Diabetic rats given methanolic extract of Smilax wightii (MESW) at the dose of $100 \mathrm{mg} / \mathrm{Kg}$ b.wt. daily for 14 days, orally by IGC

Group IV: - Diabetic rats given methanolic extract of Smilax wightii (MESW) at the dose of $200 \mathrm{mg} / \mathrm{Kg}$ b.wt. for 14 days, orally by IGC

Group V: - Diabetic rats given methanolic extract of Smilax wightii (MESW) at the dose of $400 \mathrm{mg} / \mathrm{Kg}$ b.wt. for 14 days, orally by IGC

Group VI : - Diabetic rats given Glibenclamide at the dose of $600 \mu \mathrm{g} / \mathrm{kg} / \mathrm{b} . w \mathrm{t}$. daily for 14 days, orally by IGC .

\subsection{Determination of body weight}

The rats from all the groups were weighed prior to the experiment and their initial body weights were recorded. The final body weights of the rats were recorded on the last day of experiment.

\subsection{Estimation of fasting blood glucose (FBG) levels}

Fasting blood glucose levels were measured on 0,7 and 14 days of treatment of methanolic extract of Smilax wightii (MESW) supplement from the animals of all the groups. Blood samples were obtained by nicking the tails with a sharp razor and glucose concentrations were determined using a one-touch glucometer (Johnson\& Johnson medical Ltd., Mumbai). The glucose concentration was read and documented from the glucometer readings. The results were expressed in terms of $(\mathrm{mg} / \mathrm{dl})$ of blood.

\subsection{Estimation of lipid profile}

The experimental animals from all the groups were sacrificed under light ether anaesthesia at the end of the experimental period. The rats were sacrificed by decapitation and blood was collected with anti-coagulant and the serum was used to for the estimation of lipid profile-TC-Total cholesterol (Parekh and Jung,197), TG-Triglycerides (Rice, 1970), HDL-High Density Lipoprotein (Warnick et al., 1985), LDL- Low Density Lipoprotein and VLDL Very Low Density Lipoprotein (Friedwald et al., 1972).

\subsection{Statistical Analysis}

All biochemical data are expressed as Mean \pm SEM. Statistical analysis was performed using one-way ANOVA using SPSS statistical analysis programme. In all cases, p-value less than 0.05 was considered to be significant.

\section{RESULTS}

\subsection{Toxicity studies}

Acute toxicity studies revealed that the methanolic extract of Smilax wightii (MESW) was found safe to up to a dose of $1000 \mathrm{mg} / \mathrm{kg}$ body weight. No sign of toxicity was noticed on the general health of the animals, and no death was observed in the animals when exposed to the extract.

The activity of methanolic extract of Smilax wightii (MESW) on body weight in streptozotocin induced diabetic rats are indicated in Table 1 . There was a significant weight loss in the final body weight in the diabetic control group (Group II). A significant improvement in the body weight was observed in the extract and glibenclamide treated groups when compared to that of the diabetic control group. 
Table 1: Effect of methanolic extract of S.wightii on the body weight of normal, diabetic induced and drug treated rats.

\begin{tabular}{|c|c|c|c|}
\hline $\begin{array}{l}\text { Treatment Groups } \\
(\mathrm{n}=6)\end{array}$ & $\begin{array}{l}\text { Initial body } \\
\text { weight }(\mathrm{g})\end{array}$ & $\begin{array}{l}\text { Final body } \\
\text { weight (g) }\end{array}$ & $\begin{array}{l}\text { Body weight } \\
\text { Gain }(\mathrm{G} \uparrow) / \\
\operatorname{loss}(\mathrm{L} \downarrow)(\mathrm{g})\end{array}$ \\
\hline Group II (Diabetic control) & $208.16 \pm 6.13$ & $192.13 \pm 5.84^{*}$ & $16.06 \downarrow$ \\
\hline Group III (MESW 100mg/kg) & $202.84 \pm 7.84$ & $212.17 \pm 4.36^{*}$ & $9.33 \uparrow$ \\
\hline Group IV(MESW 200mg/kg) & $198.28 \pm 3.84$ & $211.84 \pm 4.15^{*}$ & $13.56 \uparrow$ \\
\hline Group V(MESW 400mg/kg) & $210.16 \pm 7.86$ & $218.91 \pm 7.24$ & $8.72 \uparrow$ \\
\hline Group VI (Glibenclamide $600 \mu \mathrm{g} / \mathrm{kg}$ ) & $206.82 \pm 5.91$ & $215.05 \pm 5.16$ & $8.23 \uparrow$ \\
\hline
\end{tabular}

Each Value is SEM of 6 animals ${ }^{*} \mathrm{P}<0.05 ;{ }^{* *} \mathrm{P}<0.01$ comparison with Normal control vs diabetic and drug treated. a , Comparison made between diabetic control to drug treated groups Level of significance a: $\mathrm{P}<0.05$, aa: $\mathrm{P}<0.01$

Table 2: Effect of methanolic extract of $S$. wightii on fasting blood glucose levels of normal, diabetic induced and drug treated rats.

\begin{tabular}{cccc}
\hline $\begin{array}{c}\text { Treatment Groups } \\
(\mathrm{n}=6)\end{array}$ & 0 - day & $7^{\text {th }}$ day & $14^{\text {th }}$ day \\
\cline { 2 - 4 } Group I & $78.13 \pm 2.41$ & $82.18 \pm 1.93$ & $73.93 \pm 3.54$ \\
Group II & $216.13 \pm 9.13^{* *}$ & $226.31 \pm 8.16^{* *}$ & $229.75 \pm 9.15^{* *}$ \\
Group III & $193.16 \pm 5.84^{* *}$ & $131.28 \pm 7.24^{* a}$ & $102.16 \pm 4.38^{\mathrm{a}}$ \\
Group IV & $204.83 \pm 4.33^{* *}$ & $118.27 \pm 3.28^{\mathrm{a}}$ & $93.83 \pm 2.84^{\text {aa }}$ \\
Group V & $212.48 \pm 5.83^{* * *}$ & $104.38 \pm 2.84^{\text {aa }}$ & $85.16 \pm 2.13^{\text {aa }}$ \\
Group VI & $218.93 \pm 6.27^{* * *}$ & $112.18 \pm 3.16^{\text {aa }}$ & $76.83 \pm 1.84^{\text {aa }}$
\end{tabular}

Each Value is SEM of 6 animals ${ }^{*} \mathrm{P}<0.05 ;{ }^{* *} \mathrm{P}<0.01$ comparison with Normal control vs diabetic and drug treated. a,Comparison made between diabetic control to drug treated groups Level of significance a: $\mathrm{P}<0.05$, aa: $\mathrm{P}<0.01$

Table 3: Effect of methanolic extract of $S$. wightii on the serum lipid profile of normal, diabetic induced and drug treated rats.

\begin{tabular}{cccccc}
\hline $\begin{array}{c}\text { Treatment } \\
\text { Groups } \\
(\mathrm{n}=6)\end{array}$ & $\mathrm{TC}(\mathrm{mg} / \mathrm{dl})$ & $\mathrm{TG}(\mathrm{mg} / \mathrm{dl})$ & $\mathrm{HDL}(\mathrm{mg} / \mathrm{dl})$ & $\mathrm{LDL}(\mathrm{mg} / \mathrm{dl})$ & VLDL $(\mathrm{mg} / \mathrm{dl})$ \\
\hline Group I & $126.84 \pm 4.16$ & $113.88 \pm 2.14$ & $43.18 \pm 1.84$ & $60.89 \pm 2.12$ & $22.77 \pm 1.02$ \\
Group II & $198.15 \pm 3.16^{* *}$ & $165.65 \pm 3.18^{* *}$ & $23.15 \pm 1.28^{* *}$ & $141.87 \pm 2.67^{* *}$ & $33.13 \pm 1.33^{*}$ \\
Group III & $173.89 \pm 2.88^{*}$ & $141.80 \pm 3.67^{*}$ & $35.18 \pm 1.16^{*}$ & $110.03 \pm 3.62^{*}$ & $28.36 \pm 1.87$ \\
Group IV & $156.93 \pm 2.13^{*}$ & $126.67 \pm 1.93^{\text {a }}$ & $39.26 \pm 1.93$ & $92.34 \pm 1.89$ & $25.33 \pm 1.56$ \\
Group V & $134.16 \pm 2.14^{\mathrm{a}}$ & $118.31 \pm 1.88^{\mathrm{aa}}$ & $43.91 \pm 1.88^{\mathrm{a}}$ & $61.59 \pm 2.02^{\mathrm{a}}$ & $23.66 \pm 1.45^{\mathrm{a}}$ \\
Group VI & $126.48 \pm 2.09^{\mathrm{a}}$ & $135.16 \pm 2.16^{\mathrm{a}}$ & $41.93 \pm 1.65$ & $57.52 \pm 1.34$ & $27.03 \pm 1.63$ \\
\hline
\end{tabular}

Each Value is SEM of 6 animals ${ }^{*} \mathrm{P}<0.05 ;{ }^{* *} \mathrm{P}<0.01$ comparison with Normal control vs diabetic and drug treated. a, Comparison made between diabetic control to drug treated groups Level of significance a: $\mathrm{P}<0.05$, aa: $\mathrm{P}<0$.

The fasting blood glucose levels of normal, diabetic and the extract treated diabetic rats are summarized in Table 2. There was a significant $(P<0.01)$ elevation in FBG level in diabetic control group when compared to normal control group. The administration of the plant extract in STZ induced diabetic rats at doses of 100,200 and $400 \mathrm{mg} / \mathrm{kg}$ b.wt produced significant $(P<0.01)$ reduction in the 
fasting blood glucose levels. The reducing effect of the plant extract at a dose of $400 \mathrm{mg} / \mathrm{kg}$ b.wt was found to be comparable to that of the reference drug Glibenclamide $(600 \mathrm{mg} / \mathrm{kg}$ b.wt $)$. The initial reduction in blood glucose was observed on the $7^{\text {th }}$ day after the administration of the Smilax wightii extract. Meanwhile, on the $14^{\text {th }}$ day, almost the FBG levels were reduced significantly at the dose of $400 \mathrm{mg} / \mathrm{kg}$ b.wt in the extract and glibenclamide treated groups.

Table 3 depicts the changes in the levels of TC (Total Cholesterol), TG (Triglycerides), HDL (High Density Lipoprotein), LDL (Low Density Lipoprotein) and VLDL (Very Low Density Lipoprotein) of the experimental animals. Diabetes induced by STZ in rats significantly $(P<0.01)$ elevated the TC, TG, LDL, VLDL levels and decreased the HDL levels in diabetic control compared with normal control rats. In the present study, administration of MESW at dose of 100,200 and $400 \mathrm{mg} / \mathrm{kgb} . w t$ to the diabetic rats showed significant $(P<0.05, P<0.01)$ reduction in TC, TG, LDL, and VLDL levels and increase in HDL levels than diabetic control rats.

\section{DISCUSSION}

Diabetes is a major health problem affecting major populations worldwide. It is a chronic disorder in metabolism of carbohydrates, proteins, and fat due to absolute or relative deficiency of insulin secretion with/without varying degree of insulin resistance. There are more than 30 million people with diabetes mellitus in India and the incidence is increasing. Decreased physical activity, increasing obesity, stress and changes in food consumption have lead to the cause of diabetes (Jarald et al., 2008).

The present study was aimed to investigate the anti-hyperlipidemic activity of methanoic extract of S. wightii (MESW) in STZ-induced diabetic rats. The results of the study revealed that MESW at the doses of $400 \mathrm{mg} / \mathrm{kg}$ b.wt. significantly normalized elevated blood glucose level and restored serum lipid profiles towards normal values.

Streptozotocin STZ, a highly cytotoxic agent of pancreatic $\beta$-cells induces diabetes by damaging the cells and causes reduction in insulin secretion (Esmaeli and Yazdanparas, 2004). The increased glucose level in the diabetic control animals may be due to the destruction of the pancreatic cells caused by the STZ induction. The increased levels of plasma glucose in STZ-induced diabetic rats were lowered by the administration of Smilax wightii extract.
Diabetes affects both glucose and lipid metabolism (Sperling and Saunders, 2000).

Hyperlipidemia was reported as common in adults with diabetes and it is characterized most often by increased triglyceride and reduced HDL cholesterol levels. This is generally observed in both type 1 and type 2 diabetes, representing the defect of insulin action in each, either due to inadequate secretion or resistance (Garg and Grundy, 1990). Increased fatty acid concentrations also increased the $\beta$-oxidation of fatty acids, producing more acetylCoA and cholesterol in diabetics (Yokogoshi and Oda, 2000, Mard et al., 2010). Alterations in plasma lipoprotein metabolism are common in diabetes, which tend to exaggerate any pre-existing tendencies towards elevated lipid levels (Merzouk et al., 2004). The high density lipoprotein (HDL) was significantly reduced in the diabetic rats which indicate a positive risk factor for atherosclerosis (Bopanna et al., 1997). Previous studies in Smilax chinensis has reported similar results in the fasting blood glucose levels and lipid profile in Streptozotocin induced diabetic rats (Venkidesh et al., 2010). On the basis of the present study, it could be concluded that the methanolic extract of S.wightii exerted a significant antidiabetic and antihyperlipidemic effect. This could be due to different types of active principles present in the extract which serve as a good adjuvant in the present armamentarium of antidiabetic drug and has therapeutic value.

\section{REFERENCES}

Adhikari, B.S., M.M. Babu, P.L. Saklani and G.S. Rawat, (2010). Medicinal Plants Diversity and their Conservation Status in Wildlife Institute of India (WII) Campus, Dehradun. Ethnobotanical Leaflets. 14: 46-83.

Bopanna, K.N., J. Kannan, Sushma gangil, R. Blaraman, S.P. Rathod, (1997). Antidiabetic and anti hyperlipedemic effect of Neem, Lipedemic effect of Neem seed kernel powder on alloxon diabetic rabbits. Ind. J. Pharmacology. 29: 162167.

Coimbatore : Botanical Survey of India, 1989.

Esmaeili M.A., R.Yazdanparas, (2004). Hypoglycemic effect of Teucrium polium: studies with rat pancreatic islets. Journal of Ethnopharmacology. 95: $27-30$.

Fnaec, (2000). Flora of North America editorial committee. Flora of North America North of Mexico. 26: 14-46. 
Friedwald, W.T., R.I. Levy and D.S. Fredrickson, (1972). Estimation of thr concentration of low density lipoprotein cholesterol in plasma, without use of preperative ultra centrifuge. Clinical Chemistry. 18(6): 499-502.

Garg, A.and S.M. Grundy, (1990). Management of dyslipidemia in NIDDM. Diabetes Care. 113:15369.

Jarald, E., S.B. Joshi and D.C. Jain, (2008). Diabetes and Herbal Medicines. Iran. J. Pharmaco. \& Therapeut. 7(1): 97-106.

Kamboj, V.P. (2000). Herbal medicine. Current Science. 78: 35-39.

Mard, S.A., K. Jalalvand, J.M. Jafarine, H. Balochi and M.K.G Naseri, (2010). Evaluation of the antidiabetic and antilipaemic activities of the hydroalcoholic extract of Phoenix Dactylifera palm leaves and its fractions in alloxan-induced diabetic rats. The alaysian Journal of Medical Sciences. 17: 4-13.

Merzouk, S., A. Hichami, A. Sari, S. Madani, S.N. Habane and N.A. Khan, (2004). Impaired oxidant/antioxidant status and LDL-fatty acid composition are associated with increased susceptibility to peroxidation of LDL in diabetic patients. General Physiology and Biophysics. 23, 387-399.

Ozsoy, N., A. Can, R. Yanardag, N. Akev, (2008). Antioxidant activity of Smilax excelsa L. leaf extracts. Food Chem. 110: 571-583.

Parekh, A.C. and S. Jung. (1970). Cholesterol determination with ferric acetate and sulphuric acid, ferrous sulphate reagent. Analytical Chemistry. 112: 1423-1427.

Piedrola, G., E. Novo, F. Escober and R. GarciaRobles, (2001). White blood cell count and insulin resistance in patients with coronary artery disease. Ann. Endocrinol. (Paris). 62: 710.

Rajasekaran, S., K. Sivagnanam, V. Narayanan and S. Subramanian, (2001). Hypoglycemic and hypolipidemic effects of Aloevera on experimental rabbits. Publication of Indian Association of Biomedical Scientists. P. 41-45.

Rice, E.W. (1970).Triglycerides in serum in standard methods in Clinical Chemistry, Roderick MP (Ed), Academic press, New York. 6: 215-222.

Scheen, J.A. (1997). Drug treatment of non-insulin dependent diabetes mellitus in the 1990s. Achievements and future development. Drugs. 54: 355-368.

Sperling, M.A. and P.A. Saunders. (2000). Diabetes mellitus In: R.E.Behrman R.M, Kliegman, H.B, Jenson (Eds) Nelson text book of paediatrics. 1767-1791.

Venkidesh, R., Dilipkumar pal, S. Mohana Lakshmi, A. Saravanakumar and Subash C. Mandal. (2010). Antidiabetic activity of Smilax chinensis L. extract in Streptozotocin Induced diabetic rats.International J. Phytopharmacology. 1(2): 68-73.

Warnick, G.R., T. Nguyan and A. Albers. (1985). Comparison of improved precipitation method for quantification of high density lipoprotein cholesrterol. Clinical Chemistry. 31:217.

Yokogoshi, H. And H. Oda. (2002). Dietary taurine enhances cholesterol degradation and reduces serum and liver cholesterol concentrations in rats fed a high cholesterol-diet. Amino Acids. 23: 433-439. 